\title{
Incomplete Contracts and Public Ownership: Remarks, and an Application to Public-Private Partnerships
}

\author{
Oliver Hart
}

Harvard University

July 2002

\begin{abstract}
The question of what should determine the boundaries between public and private firms in an advanced capitalist economy is a highly topical one. In this paper I discuss some recent theoretical thinking on this issue. I divide the paper into two parts. First, I make some general remarks about the relationship between the theoretical literature of privatization and incomplete contracting theories of the firm. Second, I use some of the ideas from this literature to develop a very preliminary model of public private partnerships.
\end{abstract}

JEL Classification: D23, H1, H4

\section{Acknowledgements}

This paper was given at a CMPO session of the Royal Economic Society Conference 2002 (University of Warwick) on 'The Private Delivery of Public Services'. It is forthcoming in the Economic Journal (2003). I am grateful to the National Science Foundation through the National Bureau of Economic Research for financial support, and to Donald Franklin, Paul Grout, Rohan Pitchford, and Andrei Shleifer for helpful comments.

\author{
Address for Correspondent \\ Economics Department \\ Littauer Center \\ Harvard University \\ 1875 Cambridge Street \\ Cambridge \\ MA 02138
}




\section{Parallels between theories of the firm and of privatization}

Let me begin by discussing the very close parallel between the theory of the firm and the theory of privatization. ${ }^{1}$ In the vertical integration literature one considers two firms, A and B. A might be a car manufacturer and B might supply car-body parts. Suppose that there is some reason for A and B to have a long-term relationship (e.g., A or B must make a relationship-specific investment). Then there are two principal ways in which this relationship can be conducted. A and B can have an arms-length contract, but remain as independent firms; or A and B can merge and carry out the transaction within a single firm. The analogous question in the privatization literature is the following. Suppose A represents the government and B represents a firm supplying the government or society with some service. B could be an electricity company (supplying consumers) or a prison (incarcerating criminals). Then again, there are two principal ways in which this relationship can be conducted. A and B can have a contract, with B remaining as a private firm, or the government can buy (nationalize) B.

There are, of course, some important differences between the two situations. First, if B is an electricity company, it will likely have direct dealings with consumers, independent of its relationship with the government. In this case the contract the government has with a private electricity company can be thought of as an attempt to regulate the company's dealings with consumers. There is no obvious analogy in the case of vertical integration. Second, decisions to privatize or nationalize are often highly political, presumably because of the government's unique position in society, whereas vertical integration decisions are usually strictly economic. Third, the government is often thought of as a very different agent from a private firm: it is concerned with social welfare rather than just profit. Here, however, the 
distinction is less sharp than it might seem at first sight since there are a number of firms (particularly nonprofits or cooperatives) that have broader concerns than just profits.

In spite of these differences, the issues of vertical integration and privatization have much more in common than not. Both are concerned with whether it is better to regulate a relationship via an armslength contract or via a transfer of ownership. Given this, one might have expected the literatures to have developed along similar lines. However, this is not so. Whereas much of the recent literature on the theory of the firm takes an "incomplete" contracting perspective, in which inefficiencies arise because it is hard to foresee and contract about the uncertain future, much of the privatization literature has taken a "complete" contracting perspective, in which imperfections arise solely because of moral hazard or asymmetric information.

My own view is that this is unfortunate. One of the insights of the recent literature on the firm is that, if the only imperfections are those arising from moral hazard or asymmetric information, organizational form--including ownership and firm boundaries--does not matter: an owner has no special power or rights since everything is specified in an initial contract (at least among the things that can ever be specified). In contrast, ownership does matter when contracts are incomplete: the owner of an asset or firm can then make all decisions concerning the asset or firm that are not included in an initial contract (the owner has "residual control rights").

Applying this insight to the privatization context yields the conclusion that in a complete contracting world the government does not need to own a firm to control its behavior: any goals-economic or otherwise--can be achieved via a detailed initial contract. However, if contracts are incomplete, as they are in practice, there is a case for the government to own an electricity company or 
prison since ownership gives the government special powers in the form of residual control rights.

Even if this position is accepted, it does not follow that one can take an "off the shelf" model from the theory of the firm literature and apply it to privatization. In the standard "property rights" model found in that literature, ownership serves to elicit appropriate ex ante investments, particularly those in human capital. ${ }^{2}$ If firm A acquires firm B, then A, having more residual control rights, has greater bargaining power when uncontracted-for contingencies arise; A earns a greater return on her investment and therefore invests more. Conversely, B's incentive to invest falls since B's bargaining power is lower. The optimal allocation of ownership trades off these two effects.

Applying this logic to the privatization context, one concludes that, if the government buys an electricity company or prison, the benefit is that some government bureaucrat who is in charge of the prison will invest more (have more ideas, be more entrepreneurial); but the cost is that the manager of the prison--who used to be an owner but is now an employee--will invest less. The latter effect--that a government employee will be less entrepreneurial than an owner-manager--seems very plausible, but the idea that government ownership leads to more entrepreneurship by bureaucrats seems less so.

For this reason the literature has explored other trade-offs. ${ }^{3}$ Consider, for example, the model in Hart et al (1997) (HSV). HSV compare two cases. (1) The government can own a facility, a prison, say, and employ a manager to run it; or (2) the government can contract with a company owned by the prison manager to run the prison for a period of time. HSV ignore investments on the government side, but suppose that the prison manager can make two kinds of investment. He can invest in efficiencyenhancing ideas that raise the quality of prison services, e.g., develop new rehabilitation programs; he can also spend time figuring out how to cut costs and quality, while staying within the letter of the 
contract. A government employee has little incentive to engage in either activity since it is easy for the government (as owner) to "hold up" the employee without rewarding him appropriately. In contrast, a private prison owner-manager is less subject to hold up. The good news about this is that private ownership encourages the first, innovative type of investment. The bad news is that private ownership also encourages the second, quality-shading kind of investment. The choice between public and private ownership depends on which of these effects is more important.

In summary, the HSV model differs from the standard property rights model of the firm in two ways. First, only one party (the prison manager) invests, but he makes two kinds of investments (as in the multi-tasking model of Holmstrom-Milgrom (1991)). Second, the contract between the government and the prison provider plays a crucial role--it defines the extent to which quality shading can occur. In contrast, in the standard property rights model, long-term contracts are assumed to be sufficiently incomplete to be useless.

\section{Public-private partnerships (PPPs)}

In this section, I use an HSV-type model to understand the costs and benefits of public-private partnerships. ${ }^{4}$ To repeat what I said in the introduction, this model is extremely preliminary. For simplicity, I will now ignore the choice between public and private ownership and assume that all provision is private. I will take a key property of a PPP to be that facility construction and service provision are bundled, i.e., in the case of a prison the government contracts with a private party-henceforth known as the "builder"---to build and run the prison (the builder may then subcontract with someone else to run the prison). ${ }^{5}$ In contrast, under "conventional" provision, the government contracts 
with the builder to build the prison and then later on with another (private) party to run it.

There are three dates, $0,1,2$, as in Fig. 1.

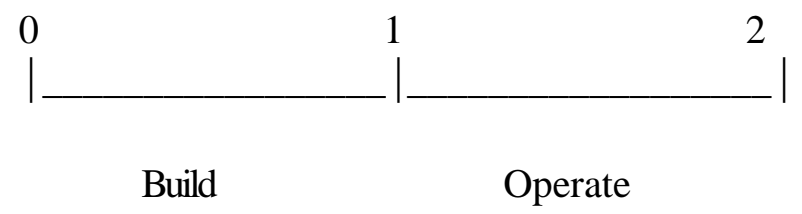

Fig. 1: Time Line

The government and builder contract at date 0 , the prison is built between dates 0 and 1 , and the prison is operated between dates 1 and 2. (There is no discounting.) The contract specifies either the basic characteristics of the prison that should be delivered at date 1 (in the case of conventional provision) or the basic prison services that should be provided between dates 1 and 2 (in the case of a PPP). ${ }^{6}$ In each case the contract is assumed to be incomplete in the sense that the builder can modify the nature of the prison or the nature of prison services in various ways, without violating the contract. Specifically, the builder can make two investments, i, e, that have consequences for the costs and benefits of running the prison between dates 1 and 2. We write

$$
\mathrm{B}=\mathrm{B}_{0}+\beta(\mathrm{i})-\mathrm{b}(\mathrm{e})
$$




$$
\mathrm{C}=\mathrm{C}_{0}-?(\mathrm{i})-\mathrm{c}(\mathrm{e})
$$

where $\beta, b, ?, c>0, \beta^{\prime}>0, b^{\prime}>0, ?^{\prime}>0, c^{\prime}>0, \beta^{\prime \prime}<0, b^{\prime \prime}>0, ?^{\prime \prime}<0, c^{\prime \prime}<0$. Here B represents the (unverifiable) benefit to society (measured in money) from running the prison and $\mathrm{C}$ represents the (unverifiable) costs from doing so (borne by the prison operator). The builder's total investment costs equal $\mathrm{i}+\mathrm{e}$.

We can interpret these investments as follows. Investment $\mathrm{i}$ is a productive investment that makes the prison more attractive and easier to run (it raises B and reduces C)--it could correspond to a higher quality / more pleasant / airier building. In contrast, e is an unproductive investment that reduces total costs and quality. It corresponds to the quality-shading investment in HSV. For example, in the process of building the prison, the builder might realize that he can install an electric fence that reduces the likelihood of escapes. This reduces prison operating costs since fewer guards have to be hired, but may not be what the government had in mind (it reduces quality).

In the first-best, $\mathrm{i}$ and e are chosen to maximize net benefit, $\mathrm{B}$ - C - i - e, i.e.,

$$
\mathrm{B}_{0}+\beta(\mathrm{i})-\mathrm{b}(\mathrm{e})-\mathrm{C}_{0}+?(\mathrm{i})+\mathrm{c}(\mathrm{e})-\mathrm{i}-\mathrm{e} \text {. }
$$

The first-order conditions are

$$
\begin{aligned}
& \beta^{\prime}\left(\mathrm{i}^{*}\right)+?^{\prime}\left(\mathrm{i}^{*}\right)=1, \\
& \mathrm{c}^{\prime}\left(\mathrm{e}^{*}\right)-\mathrm{b}^{\prime}\left(\mathrm{e}^{*}\right) \leq 1 \text { with equality if } \mathrm{e}^{*}>0 .
\end{aligned}
$$


We will assume that $c^{\prime}(0)-b^{\prime}(0) \leq 1$, i.e., e is socially unproductive. This means that we get a corner solution in the first-best: $\mathrm{e}^{*}=0$. (In contrast, all other first-order conditions are supposed to have interior solutions.)

We now consider the second-best, where the builder's investments are nonverifiable and hence can't be contracted on. We assume, however, that the provider of prison services observes i, e; in particular, he knows what his costs will be. We compare two cases.

\section{Case 1: Separate contracts to build and operate, or "unbundling"}

In this case, the government contracts with a builder at date 0 to build a basic prison for price $\mathrm{P}_{0}$. At date 1 the government auctions off the contract to operate the prison. If there is a competitive supply of contractors, the government will pay the prison operator a price equal to his operating cost $\mathrm{C}$ $=\mathrm{C}_{0}-?(\quad)-\mathrm{c}(\quad)$, where,$\quad$ are the builder's equilibrium choices of $\mathrm{i}, \mathrm{e}$. At date 0 , the builder chooses i, e to solve:

$$
\operatorname{Max} \mathrm{P}_{0}-\mathrm{i}-\mathrm{e} \text {. }
$$

The solution is extremely simple: $==0$. That is, the builder builds the cheapest prison possible (while staying within the contract). Note that, although i, e affect the operating contract price the government has to pay, the builder does not internalize this externality. ${ }^{7}$ 
If there is a competitive supply of builders, $\mathrm{P}_{0}=\quad+\quad=0$, and so the government's net payoff is

$$
\mathrm{B}-\mathrm{C}-\mathrm{P}_{0}=\mathrm{B}-\mathrm{C}-\mathrm{i}-\mathrm{e} \text {, evaluated at }=0 .
$$

\section{Case 2: PPP, or "bundling”}

In this case the government offers a contract at date 0 that specifies the basic quality of the service to be provided between dates 1 and 2 and a price P. Now the builder internalizes the cost of service provision since either he provides the service himself or he subcontracts the service (in the latter case, given competition, he will pay the subcontractor a price equal to the subcontractor's cost, $\mathrm{C}=\mathrm{C}_{0}$ - ?(i) - c(e))

At date 0 the builder chooses i, e to solve:

$$
\operatorname{Max} P-C-i-e=P-C_{0}+?(i)+c(e)-i-e .
$$

The first order conditions are

$$
\begin{aligned}
& ?^{\prime}(\quad)=1, \\
& c^{\prime}(\quad)=1 .
\end{aligned}
$$


If there is a competitive supply of builders, $\mathrm{P}=\mathrm{C}+\mathrm{i}+\mathrm{e}$, and so the government's net payoff is

$$
\mathrm{B}-\mathrm{P}=\mathrm{B}-\mathrm{C}-\mathrm{i}-\mathrm{e}, \text { now evaluated at } \mathrm{i}=, \mathrm{e}=\text {. }
$$

The PPP equilibrium is illustrated in Fig. 2 along with the first-best and the unbundling equilibrium.

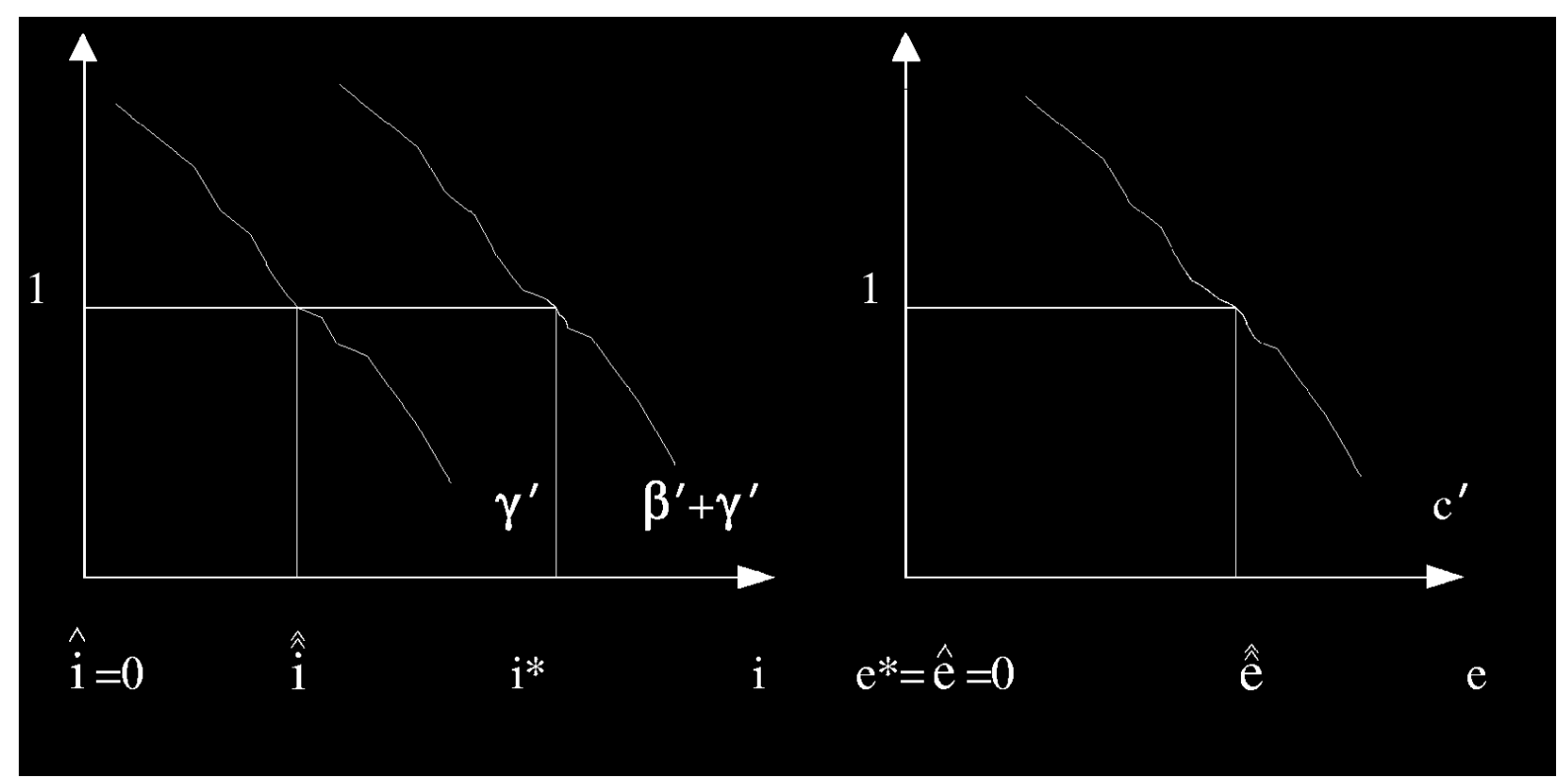

Fig. 2: Illustration of Equilibria

The trade-off between unbundling and bundling is simple. Under unbundling, the builder internalizes neither the social benefit $B$ nor the operating cost $\mathrm{C}$. By setting $\mathrm{i}=\mathrm{e}=0$, he does too little 
of the productive investment, i, but the right amount of the unproductive investment, e. In contrast, under bundling or PPP, the builder again does not internalize B, but does internalize C. As a result, he does more of the productive investment, although still too little, but also more of the unproductive investment. $^{8}$

The model yields a simple conclusion. Conventional provision ("unbundling") is good if the quality of the building can be well specified, whereas the quality of the service can't be. Under these conditions, underinvestment in i under conventional provision is not a serious issue, whereas overinvestment in e under PPP may be. In contrast, PPP is good if the quality of the service can be well specified in the initial contract (or, more generally, there are good performance measures which can be used to reward or penalize the service provider), whereas the quality of the building can't be. Under these conditions, underinvestment in i under conventional provision may be a serious issue, while overinvestment in e under PPP is not. ${ }^{9}$

It is worth being a little speculative. Arguably, prisons and schools fall into the first category: contracting on the building is relatively simple, while contracting on the service may not be. On the other hand, hospitals may fall into the second category: although specifying service quality is far from straightforward, it may be easier to come up with reasonable performance measures concerning how patients are treated than it is to specify what may be a very complex building.

\section{Final comments}

In this paper I have discussed some recent theoretical thinking on public versus private ownership, and I have developed a simple incomplete contracting model to analyze PPPs. The model 
suggests that the choice between PPPs and conventional provision turns on whether it is easier to write contracts on service provision than on building provision.

Note that, although perhaps not surprising, this conclusion is at odds with much current thinking by policy makers. Policy makers frequently argue that PPPs are good because the private sector is a cheaper source of financing or insurance than the public sector. This thinking is strange for an economist since it is hard to imagine an agent that is more able to borrow or to provide insurance than the government (with its enormous powers of taxation). One of the (modest) benefits of the current paper is that it may shift attention from what seem to be secondary financing issues to what seems to be the central issue: (relative) contracting costs.

Our model could be usefully extended in various ways. The model takes the length of contract as given-implicitly it is assumed that the world ends at date 2 . As a result, it does not matter who owns the asset (prison) at the end of the contract. With more periods, both contract length and who owns the asset after the contract ends become interesting choice variables.

The model could also be applied outside the public-private context. For example, it may throw light on the choice a purchaser in the private sector faces between hiring a general contractor to do a job and contracting separately with specialists. It may also provide ingredients for a general analysis of optimal contract length between (private) firms--an issue about which economists have had remarkably little to say. ${ }^{10}$ 


\section{REFERENCES}

Bennett, J. and Iossa, E. (2002), 'Building and managing facilities for public services,' (January) Brunel University, mimeo.

Bentz, A., Grout, P. A., and Halonen, M.. (2002), 'Public private partnerships: what should the state buy?' (March) Dartmouth College, mimeo.

Besley, T. and Ghatak, M. (2001), 'Government versus private ownership of public goods,' Quarterly Journal of Economics, vol. 116(4), pp. 1343-72.

Ellman, M. (1999), 'Essays on the economics of organizations,' Ph.D. dissertation, Harvard University.

Grout, P. A. (1997) 'The economics of the private finance initiative,' Oxford Review of Economic Policy, vol. 13(4), pp. 53-66.

Hart, O. (1995), Firms, Contracts, and Financial Structure. Oxford: Oxford University Press.

Hart, O., Shleifer, A., and Vishny, R. W. (1997), 'The proper scope of government: theory and an application to prisons,' Quarterly Journal of Economics, vol. 112(4), pp. 1126-61.

Holmstrom, B. and Milgrom, P. (1991), 'Multi-task principal-agent analyses: incentive contracts, asset ownership and job design,' Journal of Law, Economics and Organization, vol. VII , pp. 24-52.

King, S. and Pitchford, R. (2001), 'Private or public? A taxonomy of optimal ownership and management regimes,' (July), Australian National University, mimeo.

Laffont, J-J., and Tirole, J. (1993), A Theory of Incentives in Regulation and Procurement. Cambridge: MIT Press. 
Schmidt, K. (1996), 'The costs and benefits of privatization: An incomplete contracts approach,' Journal of Law, Economics and Organization, vol. XII, pp. 1-24.

Shleifer, A. (1998), 'State versus private ownership,' Journal of Economic Perspectives, vol. 12(4) (Fall) pp. 133-5 


\section{ENDNOTES}

1. For an excellent recent summary of thinking about privatization, see Shleifer (1998).

2. For a summary of the property rights literature, see Hart (1995).

3. For some representative contributions, see Schmidt (1996), Laffont and Tirole (1993), Besley and Ghatak (2001), and King and Pitchford (2001).

4. For related work, see Bentz et al (2002) and Bennett and Iossa (2002). Bennett and Iossa's model is based on incomplete contracts and is similar in a number of ways to the model presented here (it was developed independently). In contrast, Bentz et al's model emphasizes asymmetric information.

5. It is worth stressing the symmetry of the situation: it could just as well be that the government contracts with the provider of prison services, who then subcontracts with someone to build the prison.

6. In the case of a PPP, the contract can also say something about the characteristics of the prison. We discuss this point further below.

7. One can imagine that one way for the externality to be internalized is for the builder's payment $\mathrm{P}_{0}$ to be made contingent on the price the government pays to the prison operator at

date 1 . One problem with such an arrangement is that this price may not be verifiable. In any event, we will see shortly that a PPP achieves a similar outcome.

8. Note that we have implicitly assumed that the builder has the same freedom to shade on the productive investment $i$ under a PPP as under conventional provision. This makes sense if the PPP contract places the same constraints on the nature of the building as under conventional provision, along with constraints on service quality (see footnote 6). However, an often-mentioned benefit of a PPP is that one can reduce contracting costs by omitting details of the building, and focusing on service provision. The problem with this is that it may give the builder the flexibility to choose a lower $\mathrm{i}$ under PPP than under conventional provision (i.e., there is a change in the constraint set that may dominate the incentive effect discussed in the text). Thus PPPs that omit details of the building may have costs in addition to those emphasized here.

9. These conclusions about the relative desirability of PPPs mirror those in Grout (1997).

10. For some progress on this topic, however, see Ellman (1999). 